\title{
Human-directed behaviour in goats is not affected by short-term positive handling
}

\author{
Jan Langbein $^{1}\left[\right.$ ] Annika Krause ${ }^{1} \cdot$ Christian Nawroth $^{1}$
}

Received: 14 March 2018 / Revised: 22 August 2018 / Accepted: 28 August 2018 / Published online: 1 September 2018

(c) The Author(s) 2018

\begin{abstract}
In addition to domestication, interactions with humans or task-specific training during ontogeny have been proposed to play a key role in explaining differences in human-animal communication across species. In livestock, even short-term positive interactions with caretakers or other reference persons can influence human-animal interaction at different levels and over different periods of time. In this study, we investigated human-directed behaviour in the 'unsolvable task' paradigm in two groups of domestic goats (Capra aegagrus hircus). One group was positively handled and habituated to a plastic box by the experimenter to retrieve a food reward, while the other group only received standard husbandry care and was habituated to the box without human assistance. In the unsolvable task, the lid was fixed to the box, with the reward inaccessible to the subjects. The goats were confronted with the unsolvable task three times. We observed no difference between the two groups regarding gaze and contact alternations with the experimenter when confronted with the task they cannot solve by themselves. The goats did not differ in their expression rates of both gaze and contact alternations over three repetitions of the unsolvable task; however, they showed earlier gaze and contact alternations in later trials. The results do not support the hypothesis that short-term positive handling or task-specific training by humans facilitates human-directed behaviour in goats. In contrast, standard husbandry care might be sufficient to establish humans as reference persons for farm animals in challenging situations.
\end{abstract}

Keywords Domestication · Human-animal interaction · Intentional communication · Livestock · Ontogeny $\cdot$ Referential communication $\cdot$ Social cognition

\section{Introduction}

It has been argued that domestication has turned animals, such as the dog (Canis lupus familiaris), the cat (Felis silvestris catus), the horse (Equus ferus caballus), the pig (Sus scrofa domesticus) and the goat (Capra aegagrus hircus), at different levels, into specialists in the field of heterospecific communication with humans (Pfungst 1907; McKinley and Sambrook 2000; Hare et al. 2002; Miklósi et al. 2003, 2005; Kaminski et al. 2005; Maros et al. 2008). Several

Electronic supplementary material The online version of this article (https://doi.org/10.1007/s10071-018-1211-1) contains supplementary material, which is available to authorized users.

Jan Langbein

langbein@fbn-dummerstorf.de

1 Leibniz Institute for Farm Animal Biology, Institute of Behavioural Physiology, Wilhelm-Stahl-Allee 2, 18196 Dummerstorf, Germany non-mutually exclusive hypotheses have been proposed to explain the differences in this cognitive domain between domestic animals and their wild counterparts. According to the 'domestication hypothesis', during thousands of years of co-evolution with humans, domestic animals have developed specific human-directed social skills (Hare and Tomasello 2005; Miklósi et al. 2007; Riedel et al. 2008; Nawroth et al. 2014; Lampe et al. 2017). They show enhanced sensitivity to human ostensive cues and an understanding of human communicative gestures that are unique among non-human animals. Controlled artificial selection for tameness and fearlessness towards humans has led to the development of socio-cognitive traits in an experimental population of silver foxes (Hare et al. 2005), and heritability estimates have shown that human-directed behaviour in dogs has a genetic basis (Persson et al. 2015).

This 'domestication hypothesis' has been critically discussed by many scholars, as it largely ignores environmental influences on the development of human-directed 
social skills during ontogenesis (Udell et al. 2008; Wynne et al. 2008). Several authors have stressed that, in addition to domestication, lifetime experience, the degree of socialization with humans during ontogenesis, and the level of training by humans based on conditioning can have an impact on the understanding of human social cues and human attentional states by domestic companion animals (Marshall-Pescini et al. 2008, 2009; Zaine et al. 2015). This has led to the 'two-stage hypothesis' (Udell et al. 2010), which emphasizes that in addition to the role of domestication, habituation to humans early in ontogeny combined with repeated conditioning is mainly responsible for the improved reading and interpretation of human cues in domestic animals (Reid 2009; Passalacqua et al. 2011; Proops et al. 2013; D'Aniello et al. 2015, 2017). However, while domestic companion animals, such as dogs, cats and horses, often experience intensive human-animal relationships during their lifetime, domestic animals bred for production purposes, such as goats and pigs, usually have little individual positive human-animal contact. To date, it is not known how ontogenetic factors, such as human contact in the context of housing and management, can impact farm animals' humandirected behaviour.

An important aspect of human-directed behaviour is the use of gazes and gaze alternations as a method of human-animal communication (Jakovcevic et al. 2010; Teglas et al. 2012; Nagasawa et al. 2015). Gazing at humans or even tactile contact are used by several domestic companion animals as a communicative cue to alter the behaviour of a human when the animals are faced with a situation they cannot solve by themselves (Miklósi et al. 2000). A test paradigm that is often used to demonstrate gazing in the context of complex human-animal interactions is the "unsolvable task' paradigm (Miklósi et al. 2003). Subjects are confronted with a task in which a food reward is inaccessible while they have the opportunity to interact with a human experimenter. As with other behaviours in the context of human-animal communication, in addition to the notion that domestication has favoured gazing at humans in this situation (Miklósi et al. 2003), various ontogenetic influences have also been studied. This includes breed, age and previous training experiences (Marshall-Pescini et al. 2013, 2017; D'Aniello and Scandurra 2016).

Specific aspects of dogs' human-directed behaviour in this task (e.g. gaze and contact alternations) are regarded as referential and intentional communication (MarshallPescini et al. 2013) and have also been reported for other domestic companion animals, such as horses (Malavasi and Huber 2016). Recently, a domestic non-companion animal, the goat, has been shown to display similar referential and intentional-like behaviour in this task (Nawroth et al. 2016). The goats tested in that study had experienced year-long positive human interaction, which probably favoured begging and attention-getting behaviour towards humans through positive reinforcement and/or the establishment of a referential problem space (Leavens et al. 2005). Thus, these long-term positive interactions might have altered goats' behaviour in the unsolvable task.

In various livestock species, even limited positive interactions with the caretaker or another reference person can influence human-animal interaction at different levels and over different periods of time (Waiblinger et al. 2006). Chickens that were handled twice a day for 11 days from the day after hatching showed reduced fear of the handler and other humans after the handling (Jones 1994). Calves that had minimal human contact during rearing allowed the familiar experimenter to touch their heads more quickly later in life than could an unknown experimenter (Boivin et al. 1998). Furthermore, calves readily discriminate handlers with whom they have had positive interactions from handlers with whom they have had negative experience after only a few positive treatment sessions (dePassille et al. 1996); friendly treated lambs distinguish familiar people from unknown people, while negatively treated lambs generalize their fear reaction to familiar and unknown people (Destrez et al. 2013). Pigs also generalize their behaviour towards humans (Tanida et al. 1995; Terlouw and Porcher 2005). With regard to learning, horses that have been handled by humans for 2-3 weeks at different ages achieved consistently higher learning performance in a T-maze at an age of 2 years than did to horses that received only standard handling (Heird et al. 1986). In addition, the repeated provisioning of a reward in a learning task in horses increases positive animal-human interactions not only in the context of the learning task but also several months later, despite no further positive interactions; the animals also generalize this positive attitude towards all humans (Sankey et al. 2010).

In this study, we investigated human-directed behaviour of two groups of goats using the 'unsolvable task' paradigm. One group ('handled') received positive human-animal interaction in the home pen twice a day over a period of 2 weeks and special training on the task by a human trainer for 5 days before the test. A second group ('non-handled') only experienced standard human contact during daily management routines in the time before the test. In contrast to previous studies that usually administered a single unsolvable test trial in the 'unsolvable task' paradigm, we here have performed multiple test trials with each subject to examine how repeated confrontation with an unsolvable task affects human-directed behaviour in the goat. Based on the positive handling and training in the 'handled' group, we expected a higher degree of human-directed behaviour in this group. However, we cannot rule out the possibility that lifelong exposure to humans during standard husbandry care could have led to this behaviour. 


\section{Animals, materials and methods}

\section{Animals}

Twenty Nigerian Dwarf goats (all female, 10-16-month-old) were housed and managed indoors in two groups of ten animals each at the "Experimental Animal Goat Facility" of the Leibniz Institute of Farm Animal Biology (FBN) in accordance with the appropriate housing regulations. At this age, goats have reached sexual as well as breeding maturity. The animals were not food-deprived in any phase of handling, training or testing.

\section{Treatment-specific handling and habituation}

All goats had contact with humans throughout their lives in the context of standard farm management practices, e.g. weaning, regrouping and daily routines (feeding and cleaning the pen). They had no experience with food-rewarded tasks prior to the experiment.

Directly before Training and Test (see below), one group ('handled') was handled by a human experimenter, who interacted with the animals in their home pen through friendly talking, gentle touching, stroking and hand feeding. This procedure was repeated for $30 \mathrm{~min}$ twice daily over 2 weeks. A second group ('non-handled') did not receive this kind of human contact. After the handling phase, both groups were habituated in their respective home pen to a transparent plastic box $(10 \times 5 \times 15 \mathrm{~cm})$ that was used later in training and test trials. The box was mounted on a plank attached to the wall at a height of $47 \mathrm{~cm}$. A moveable plastic lid could be easily pushed to the side if unfixed, allowing access to the reward in the box (a piece of uncooked pasta). Only in the handled group, the experimenter showed the goats how to interact with the box by demonstrating and assisting with removing the loosely fitted lid to allow access to the food reward, with every subject experiencing approximately two successful interactions with the box per session. In the non-handled group, the experimenter left the pen every time after baiting the box and was not present while the goats learned how to interact with the box to open the lid. Once an individual experienced two successful box interactions per session, this individual was removed from the group until the end of the session to avoid monopolization of the box. In both groups, the procedure was repeated in two sessions per day over 5 days.

\section{Training}

After handling and habituation, goats were trained and tested individually in a separate compartment. For a training or test session, the group was transferred from the home pen to the waiting area (Fig. 1). For each trial, an individual goat was gently pushed into the start area $(1 \times 1 \times 1 \mathrm{~m})$ adjacent to the test arena $(2.9 \times 2.6 \mathrm{~m})$. The areas were connected by a transparent, acrylic guillotine door (Fig. 1). A plastic box identical to the one used in the home pen was attached to the test arena wall opposite the guillotine door at a height of $47 \mathrm{~cm}$. The experimenter baited the box in full view of the goat waiting in the start area, put the lid loosely on top, sat on a stool approximately $1.5 \mathrm{~m}$ from the box and remained neutral with her gaze directed towards the opposite wall (Fig. 2a). The guillotine door was lifted after $10 \mathrm{~s}$, and the goat could move freely around the test arena and manipulate the box to reach the food reward for $60 \mathrm{~s}$. The difficulty
Fig. 1 Sketch of the experimental setup

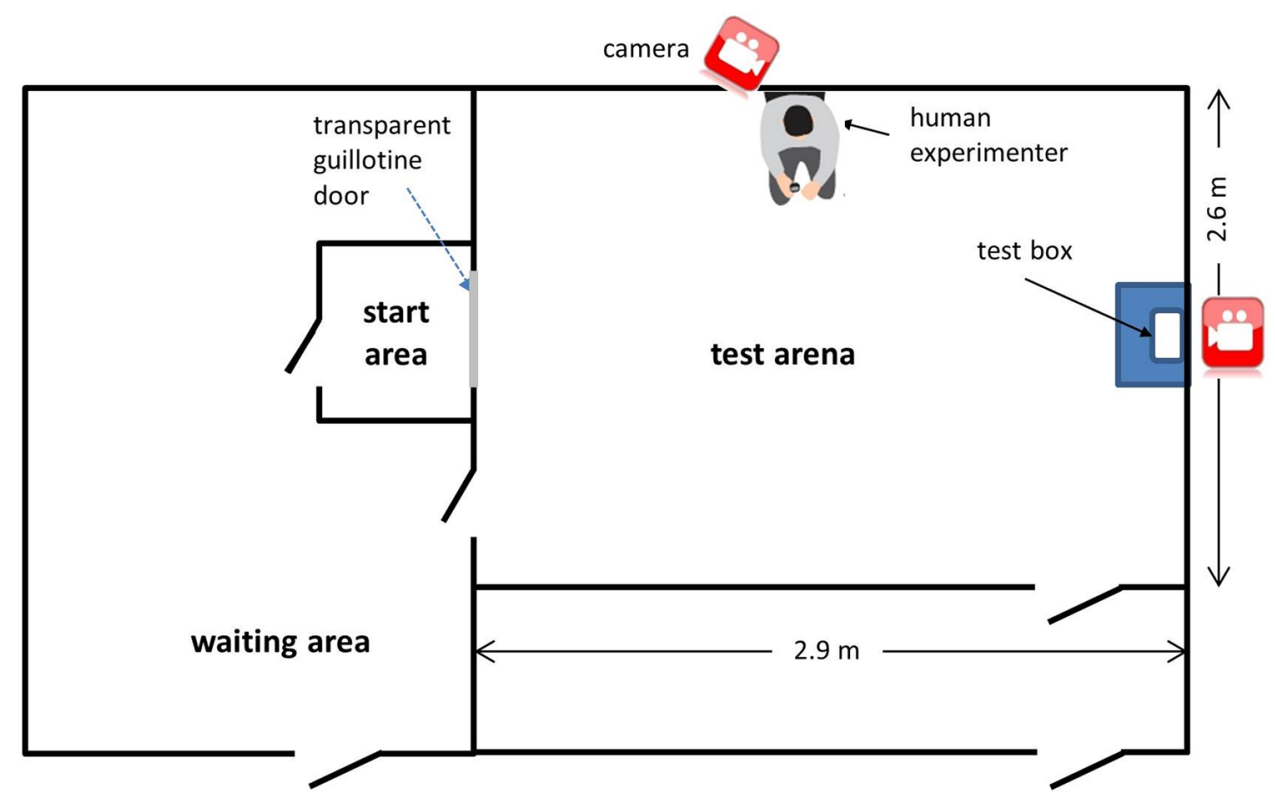



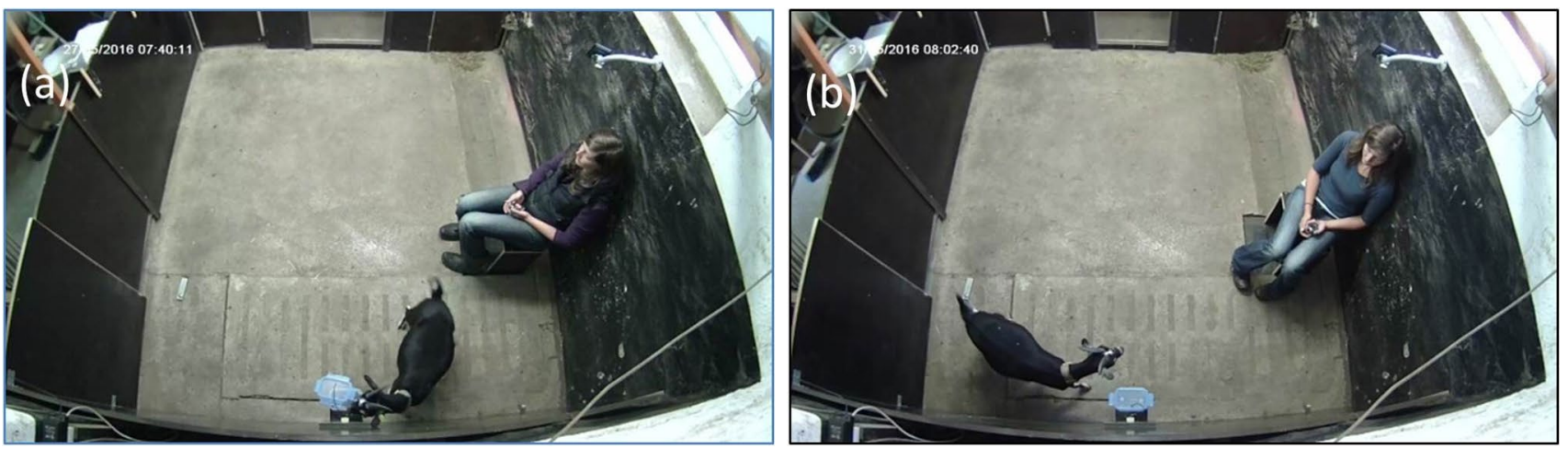

Fig. 2 Human experimenter in the test arena a positioned in a neutral position in the solvable training and motivation trials and $\mathbf{b}$ directed towards the box in the unsolvable test trials

in opening the box was individually adjusted. In the first training trial, the box was open (without a lid) for all subjects. When the goat retrieved the reward, the lid was placed orthogonally in the following trial, then diagonally and then placed directly on top. A training trial finished when the subject succeeded in opening the box and retrieving the food reward or after $60 \mathrm{~s}$. After a trial, the subject was moved back to the waiting area (see ESM_V1). Each subject completed four training trials per day over 5 days. The learning criterion was set to six successful trials in a row within 20 trials with the lid put on correctly.

\section{Test}

The test trial procedure (unsolvable) was identical to the solvable training trials except that the lid was fixed to the box with the food reward visible but inaccessible to the subjects, and the experimenter was now facing the box (Fig. 2b). Each subject completed three unsolvable test trials ( $60 \mathrm{~s}$ each) on three consecutive days (see ESM_V1). To keep the subjects motivated to approach the box and obtain the food reward, two motivation trials (solvable, identical to training) were performed prior to each test trial.

\section{Data scoring}

All trials were recorded using two video cameras (Panasonic WV-CP500 linked to EverFocus recorder EDRHD-4H4 and Panasonic HDC-SD60). One was attached from above to record goat behaviour in the complete test arena (Fig. 2), and one was attached next to the experimenter with a view of the box to record the gaze interaction between the goat and the box/experimenter in detail. For training trials and solvable motivation trials, the time from entering the test arena until retrieving the reward was recorded to evaluate whether reduced latencies occurred in retrieving the food reward across groups or repetitions. In the solvable and unsolvable trials, we coded specific behaviours, particularly the human-directed (gaze and contact alternations) and taskdirected (time in physical contact with the box) behaviours listed in Table 1.

Task-directed behaviour (time in physical contact with the box) was recorded as indicating motivation to retrieve the food reward. Data were analysed using Observer XT (The Observer 11.0, Noldus, Wageningen, Netherlands). To assess inter-observer reliability, a second observer, not involved in the study, coded the full behavioural sequence of $30 \%$ of the test trials. Cohen's kappa indicated excellent

Table 1 Coded behaviours in the unsolvable test trials

\begin{tabular}{lll}
\hline & Behaviour & Definition \\
\hline Task-directed behaviour & Time in physical contact with the box (duration) & $\begin{array}{c}\text { Any goat behaviour related to physical contact with the box: } \\
\text { nosing, smelling, rubbing, licking, biting, or pushing } \\
\text { The goat turned its head (within 3 s) from the box towards the } \\
\text { experimenter (simple gaze alternation) and back to box (two- } \\
\text { fold gaze alternation) }\end{array}$ \\
& Contact alternation (frequency and latency) & $\begin{array}{c}\text { Coming directly (within } 5 \mathrm{~s} \text { ) from the box, the goat established } \\
\text { physical contact with the experimenter (simple contact alter- } \\
\text { nation) and back with the box (twofold contact alternation) }\end{array}$ \\
\hline
\end{tabular}


agreement between coders across all coded behaviours $(\kappa=0.88, p<0.001$; The Observer 12.0).

\section{Statistical analysis}

The mean number of trials to reach the training criterion was compared between the groups using the Mann-Whitney $U$ test. The number of animals showing gaze and contact alternations in the handled and non-handled groups in the unsolvable test trials were compared using a Chi-square "goodness-of-fit" test.

In SAS (version 9.3, 2009, SAS Institute Inc., Cary, NC, USA), we analysed latency to retrieve the reward in the training trials, gaze and contact alternations, and gaze and contact latency and time in physical contact with the box in the test trials using generalized linear mixed models (GLIMMIX procedure) with group (handled, non-handled), repetition (training trials: 16-20; unsolvable trials: $1-3$; solvable motivation trials: $1-6$ ) and their interactions as fixed effects, with the appropriate distributions (Poisson or normal) and link functions (log or identity). When analysing the gaze and contact alternation latencies, animals not exhibiting this behaviour were excluded from analysis. All analyses included the subject as a repeated factor. The alpha level was set at 0.05 . Least-square means (LSMs) and their standard errors (SEs) were computed for each fixed effect in the model.

\section{Results}

\section{Training}

All goats reached the criterion of six successful trials in a row within 20 trials. The mean number of the sixth consecutive successful trial was $15.6( \pm 2.07)$ in the handled group and $15.3( \pm 1.42)$ in the non-handled group $(U=50.5$, $\mathrm{p}=0.53)$. Mean latency to retrieve the reward in the final five training trials was $7.70 \mathrm{~s}( \pm 2.35)$ in the handled group and $7.10 \mathrm{~s}( \pm 0.94)$ in the non-handled group with no difference between groups $\left(F_{1,18}=0.082, p=0.778\right)$ or trials $\left(F_{4,18}=2.711, p=0.063\right)$. During training, none of the goats exhibited any gaze or contact alternations towards the human experimenter.

\section{Test}

Groups did not differ in their latency to retrieve the reward in the solvable motivation trials $\left(F_{1,18}=0.003, p=0.955\right)$, while both groups decreased their latency times over trials $\left(F_{5,18}=2.917, p=0.042\right)$. As during training, in the solvable motivation trials, the goats did not exhibit gaze or contact alternations towards the human experimenter. In the unsolvable trials, no difference between groups was found in their time to interact with the box $\left(F_{1,18}=0.163, p=0.691\right)$, while interaction times decreased over trials $\left(F_{2,18}=73.993\right.$, $p<0.001$; Fig. 3a). The number of goats that gaze alternated at the experimenter in the three unsolvable trials was 7,9 and 10 (of 10) in the handled group and 8, 10 and 9 (of $10)$ in the non-handled group (all $p>0.05)$. Group $\left(F_{1,17.9}\right.$ $=2.478, p=0.133)$ and trial $\left(F_{2,17.7}=2.635, p=0.099\right)$ had no impact on the number of gaze alternations (Fig. 3b). The number of goats alternating contact with the experimenter in the three unsolvable trials was 3, 7 and 7 (of 10) in the handled group and 5, 6 and 4 (of 10) in the non-handled group (all $p>0.05$ ). Again, no differences were observed between groups $\left(F_{1,16.0}=0.076, p=0.786\right)$ or trials $\left(F_{2,17.0}\right.$ $=0.868, p=0.437)$ in the number of contact alternations (Fig. 3c). Finally, groups did not differ in the latency to their first gaze alternation $\left(F_{1,14.5}=1.430, p=0.251\right.$; Fig. $\left.3 \mathrm{~d}\right)$ or to their first contact alternation $\left(F_{1,10.3}=0.190, p=0.672\right.$; Fig. 3e); however, latency times decreased across trials for both measures $\left(F_{2,15.4}=42.057, p<0.001 ; F_{2,10.1}=32.925\right.$, $p<0.001$, respectively).

\section{Discussion}

Positive short-term interactions can affect general behavioural patterns towards humans in livestock animals (Tallet et al. 2009; Brajon et al. 2015; Muns et al. 2015). Whether these changes also extend to more sophisticated human-animal interactions is not yet clear. In this study, we compared the level of human-directed behaviour between goats that only experienced standard handling during husbandry care and goats that received short-term positive handling for 3 weeks prior to testing in the 'unsolvable task' paradigm. We show that goats which received only standard handling already show frequent referential- and intentional-like human-directed behaviour, such as gaze and contact alternations, and that this behaviour is not facilitated by additional short-term positive handling. This finding indicates that goats show elements of referential and intentional communication after only standard handling by humans over the course of ontogeny (Marshall-Pescini et al. 2017).

Goats housed at a sanctuary have been reported to show frequent gaze and contact alternations to communicate in a referential and intentional way with humans (Nawroth et al. 2016). Daily positive human interactions, including frequently receiving rewards, may have sufficiently facilitated these behavioural patterns through positive reinforcement (Elgier et al. 2009). Contrary to this ontogenetic explanation, we found that goats which received only standard handling with limited exposure to humans prior to testing showed levels of human-directed behaviour similar to those of intensively handled sanctuary goats. In addition, daily positive 

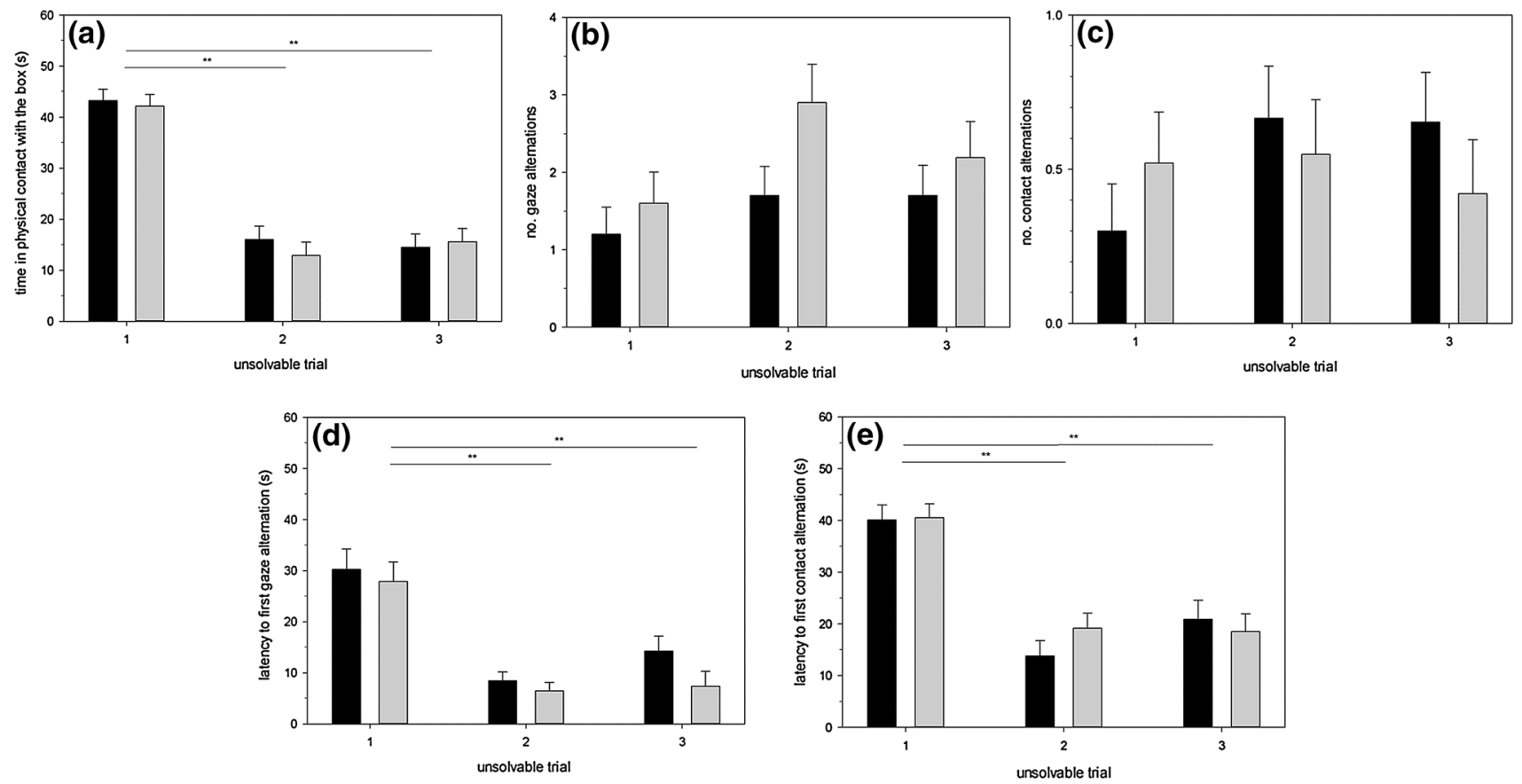

Fig. 3 Least-square means $( \pm$ SEs) for (a) time in physical contact with the box, number of (b) gaze alternations and (c) contact alternations towards the human experimenter and latency to (d) first gaze or (e) contact alternation in three unsolvable trials for two groups of

goats with different human-animal interaction backgrounds. Black bars: handled group; grey bars: non-handled group. Lines with asterisks above the bars indicate significant differences between repetitions $(* * p<0.01)$

and task-related interactions with humans for 3 weeks did not increase the occurrence of gaze and contact alternations. This indicates that short-term positive handling does not affect human-directed behaviour. However, longer-lasting exposure to positive interactions with humans may have a more profound impact (D'Aniello et al. 2015; D'Aniello and Scandurra 2016).

In dogs, ontogenetic factors can alter their expression of human-directed behaviour: socially deprived subjects showed lower levels of gazing behaviour than did pet dogs in the unsolvable task paradigm (D'Aniello and Scandurra 2016). Moreover, dogs that received specific long-term training routines unrelated to the task, such as water-rescue dogs, also showed increased gazing behaviour towards humans (D'Aniello et al. 2015; Scandurra et al. 2015). Therefore, long-term positive interactions and/or specific handling routines might also change the human-directed behaviour of goats. Short-term positive handling and prior training in the task did not affect the human-directed behaviour in our goats. One reason for this result might be that treatment was only induced over a total of 3 weeks, which might have been too short a time to affect the behaviour of the goats. As an alternative explanation, human-directed behaviour in our subjects was already at a similar high level compared with that of highly habituated and handled sanctuary goats (Nawroth et al. 2016), indicating that the expression of their human-directed behaviour had already reached a ceiling.

For dogs, human-directed behaviour has been shown in puppies with very limited experience with humans (Marshall-Pescini et al. 2013). This indicates that for dogs, no or only very limited prior exposure to humans is sufficient to elicit this behaviour. Goats in our study were aged between 1 and 1.5 years, but their experience with humans prior to testing was reduced to daily management routines and veterinary practices. These routines included practices that are unlikely to be perceived as positive by the animals, such as claw trimming. In addition, daily husbandry routines, such as feeding, never focused on one animal alone, but always on the group. One explanation for our findings could be that goats, as domestic species, are predisposed to exhibit referential and intentionally communicative behaviour (see Miklósi et al. 2003 and; Marshall-Pescini et al. 2014 for dogs). During domestication, goats were selected for decreased emotional reactivity towards humans and for production traits, such as milk yield, but not for direct cooperation with humans. However, selection for other traits, such as suitability for herding by humans, might have indirectly affected their human-directed communication and cognitive skills (Mlekuz 2013). Tests with wild goats and domestic goats without prior human contact are needed to support this claim but are difficult to conduct-goats are prey animals, and stress responses caused by being in close proximity to humans will likely mask potential human-directed behaviours. Alternatively, ontogenetic factors related to 
human experience, such as the brief contact with humans during standard husbandry practices, may sufficiently affect livestock behaviour and might be responsible for the level of human-directed behaviours seen in our control group (Munksgaard et al. 1997; Lansade et al. 2005; Sankey et al. 2010).

The impact of repeatedly exposing the goats to the 'unsolvable task' paradigm on human-directed behaviour and their motivation to solve the task has rarely been evaluated (but see Malavasi and Huber 2016). Our goats did not differ in their expression rates of both gaze and contact alternations over three repetitions of the unsolvable task, even though the experimenter never interacted with the box or the animals during test trials (Bentosela et al. 2008). In contrast, goats showed gaze or contact alternations earlier in later trials, while their time interacting with the box decreased. These decreasing interaction times could indicate that human-directed behaviour is not caused by the simple frustration of being unable to open the box, and that instead, it occurs once subjects realize that the problem is unsolvable. This supports the interpretation that the goats use gaze and contact alternations as elements of referential and intentional communication. However, future experiments that control for human presence during the unsolvable trial are needed to disentangle the subject's realization of needing help and a simple decrease in motivation to open the box.

In conclusion, our results do not support the hypothesis that short-term positive handling or task-specific training by humans facilitates human-directed behaviour in goats. In contrast, we found that goats receiving only standard handling during husbandry care already showed frequent human-directed behaviour when confronted with the unsolvable task. Further research needs to address whether and what amount of human interaction is necessary for livestock species, such as goats, to exhibit these human-directed behaviours.

Acknowledgements We would like to thank Dieter Sehland and Heinz Deike for excellent technical assistance, Katrin Siebert for data coding, Armin Tuchscherer for statistical advice, and Juliane Kaminski for providing very helpful comments on a previous version of the manuscript. Finally, we thank the section editor and two anonymous reviewers for their helpful comments on an earlier version of this manuscript. The publication of this article was funded by the Open Access Fund of the Leibniz-Institute for Farm Animal Biology (FBN).

Author contributions JL and AK conceived/designed the study; AK and JL conducted experiments and analysed the data; all authors wrote the manuscript. All authors gave final approval for publication and agree to be held accountable for the work performed.

Data accessibility The raw data are available as ESM.

\section{Compliance with ethical standards}

Conflict of interest The authors declare that they have no conflict of interest.

Ethical approval All procedures involving animal handling and treatment were approved by the Committee for Animal Use and Care of the Ministry of Agriculture of Mecklenburg-Vorpommern, Germany (Ref. Nr. 7221.3-2-011/16).

Open Access This article is distributed under the terms of the Creative Commons Attribution 4.0 International License (http://creativeco mmons.org/licenses/by/4.0/), which permits unrestricted use, distribution, and reproduction in any medium, provided you give appropriate credit to the original author(s) and the source, provide a link to the Creative Commons license, and indicate if changes were made.

\section{References}

Bentosela M, Barrera G, Jakovcevic A, Elgier AM, Mustaca AE (2008) Effect of reinforcement, reinforcer omission and extinction on a communicative response in domestic dogs (Canis familiaris). Behav Processes 78:464-469. https://doi.org/10.1016/j.bepro c. 2008.03 .004

Boivin X, Garel JP, Mante A, Le Neindre P (1998) Beef calves react differently to different handlers according to the test situation and their previous interactions with their caretaker. Appl Anim Behav Sci 55:245-257. https://doi.org/10.1016/s0168-1591(97)00050-6

Brajon S, Laforest JP, Bergeron R, Tallet C, Hotzel MJ, Devillers N (2015) Persistency of the piglet's reactivity to the handler following a previous positive or negative experience. Appl Anim Behav Sci 162:9-19. https://doi.org/10.1016/j.applanim.2014.11.009

D'Aniello B, Scandurra A (2016) Ontogenetic effects on gazing behaviour: a case study of kennel dogs (Labrador Retrievers) in the impossible task paradigm. Anim Cogn 19:565-570. https://doi. org/10.1007/s10071-016-0958-5

D’Aniello B, Scandurra A, Prato-Previde E, Valsecchi P (2015) Gazing toward humans: a study on water rescue dogs using the impossible task paradigm. Behav Process 110:68-73. https://doi. org/10.1016/j.beproc.2014.09.022

D’Aniello B, Alterisio A, Scandurra A, Petremolo E, Iommelli MR, Aria M (2017) What's the point? Golden and Labrador retrievers living in kennels do not understand human pointing gestures. Anim Cogn 20:777-787. https://doi.org/10.1007/s1007 1-017-1098-2

dePassille AM, Rushen J, Ladewig J, Petherick C (1996) Dairy calves' discrimination of people based on previous handling. J Anim Sci 74:969-974

Destrez A, Coulon M, Deiss V, Delval E, Boissy A, Boivin X (2013) The valence of the long-lasting emotional experiences with various handlers modulates discrimination and generalization of individual humans in sheep. J Anim Sci 91:5418-5426. https://doi. org/10.2527/jas.2012-5654

Elgier AM, Jakovcevic A, Barrera G, Mustaca AE, Bentosela M (2009) Communication between domestic dogs (Canis familiaris) and humans: dogs are good learners. Behav Process 81:402-408. https ://doi.org/10.1016/j.beproc.2009.03.017

Hare B, Tomasello M (2005) Human-like social skills in dogs? Trends Cogn Sci 9:439-444. https://doi.org/10.1016/j.tics.2005.07.003

Hare B, Brown M, Williamson C, Tomasello M (2002) The domestication of social cognition in dogs. Science 298:1634-1636. https:// doi.org/10.1126/science. 1072702 
Hare B, Plyusnina I, Ignacio N, Schepina O, Stepika A, Wrangham $\mathrm{R}$, Trut L (2005) Social cognitive evolution in captive foxes is a correlated by-product of experimental domestication. Curr Biol $15: 226-230$

Heird JC, Whitaker DD, Bell RW, Ramsey CB, Lokey CE (1986) The effects of handling at different ages on the subsequent learning ability of 2-year-old horses. Appl Anim Behav Sci 15:15-25

Jakovcevic A, Elgier AM, Mustaca AE, Bentosela M (2010) Breed differences in dogs' (Canis familiaris) gaze to the human face. Behav Process 84:602-607. https://doi.org/10.1016/j.beproc.2010.04.003

Jones RB (1994) Regular handling and the domestic chick's fear of human beings: generalisation of response. Appl Anim Behav Sci 42:129-143. https://doi.org/10.1016/0168-1591(94)90153-8

Kaminski J, Riedel J, Call J, Tomasello M (2005) Domestic goats, Capra hircus, follow gaze direction and use social cues in an object choice task. Anim Behav 69:11-18. https://doi.org/10.1016/j. anbehav.2004.05.008

Lampe M, Brauer J, Kaminski J, Viranyi Z (2017) The effects of domestication and ontogeny on cognition in dogs and wolves. Sci Rep 7:11690. https://doi.org/10.1038/s41598-017-12055-6

Lansade L, Bertrand M, Bouissou M-F (2005) Effects of neonatal handling on subsequent manageability, reactivity and learning ability of foals. Appl Anim Behav Sci 92:143-158. https://doi. org/10.1016/j.applanim.2004.10.014

Leavens DA, Hopkins WD, Bard KA (2005) Understanding the point of chimpanzee pointing: epigenesis and ecological validity. Curr Dir Psychol Sci 14:185-189. https://doi.org/10.111 1/j.0963-7214.2005.00361.x

Malavasi R, Huber L (2016) Evidence of heterospecific referential communication from domestic horses (Equus caballus) to humans. Anim Cogn 19:899-909. https://doi.org/10.1007/s1007 1-016-0987-0

Maros K, Gacsi M, Miklosi A (2008) Comprehension of human pointing gestures in horses (Equus caballus). Anim Cogn 11:457-466. https://doi.org/10.1007/s10071-008-0136-5

Marshall-Pescini S, Valsecchi P, Petak I, Accorsi PA, Previde EP (2008) Does training make you smarter? The effects of training on dogs' performance (Canis familiaris) in a problem solving task. Behav Process 78:449-454. https://doi.org/10.1016/j.bepro c. 2008.02.022

Marshall-Pescini S, Passalacqua C, Barnard S, Valsecchi P, PratoPrevide E (2009) Agility and search and rescue training differently affects pet dogs' behaviour in socio-cognitive tasks. Behav Process 81:416-422. https://doi.org/10.1016/j.beproc.2009.03.015

Marshall-Pescini S, Colombo E, Passalacqua C, Merola I, Prato-Previde $\mathrm{E}$ (2013) Gaze alternation in dogs and toddlers in an unsolvable task: evidence of an audience effect. Anim Cogn 16:933-943. https://doi.org/10.1007/s10071-013-0627-x

Marshall-Pescini S, Ceretta M, Prato-Previde E (2014) Do domestic dogs understand human actions as goal-directed? PLoS One 9:e106530. https://doi.org/10.1371/journal.pone.0106530

Marshall-Pescini S, Rao A, Virányi Z, Range F (2017) The role of domestication and experience in 'looking back' towards humans in an unsolvable task. Sci Rep 7:46636. https://doi.org/10.1038/ srep46636

McKinley J, Sambrook TD (2000) Use of human-given cues by domestic dogs (Canis familiaris) and horses (Equus caballus). Anim Cogn 3:13-22. https://doi.org/10.1007/s100710050046

Miklósi Á, Polgárdi R, Topál J, Csányi V (2000) Intentional behaviour in dog-human communication: an experimental analysis of "showing" behaviour in the dog. Anim Cogn 3:159-166. https:// doi.org/10.1007/s100710000072

Miklósi Á, Kubinyi E, Topál J, Gácsi M, Virányi Z, Csányi V (2003) A simple reason for a big difference: wolves do not look back at humans, but dogs do. Curr Biol 13:763-766. https://doi. org/10.1016/S0960-9822(03)00263-X
Miklósi Á, Pongracz P, Lakatos G, Topál J, Csányi V (2005) A comparative study of the use of visual communicative signals in interactions between dogs (Canis familiaris) and humans and cats (Felis catus) and humans. J Comp Psychol 119:179-186. https://doi. org/10.1037/0735-7036.119.2.179

Miklósi Á, Topál J, Csányi V (2007) Big thoughts in small brains? Dogs as a model for understanding human social cognition. Neuroreport 18:467-471. https://doi.org/10.1097/WNR.0b013e3280 287aae

Mlekuz D (2013) The birth of the herd. Soc Anim 21:150-161. https ://doi.org/10.1163/15685306-12341299

Munksgaard L, DePassille AM, Rushen J, Thodberg K, Jensen MB (1997) Discrimination of people by dairy cows based on handling. J Dairy Sci 80:1106-1112. https://doi.org/10.3168/jds. S0022-0302(97)76036-3

Muns R, Rault JL, Hemsworth P (2015) Positive human contact on the first day of life alters the piglet's behavioural response to humans and husbandry practices. Physiol Behav 151:162-167. https://doi. org/10.1016/j.physbeh.2015.06.030

Nagasawa M et al (2015) Oxytocin-gaze positive loop and the coevolution of human-dog bonds. Science 348:333-336. https://doi. org/10.1126/science. 1261022

Nawroth C, Ebersbach M, von Borell E (2014) Juvenile domestic pigs (Sus scrofa domestica) use human-given cues in an object choice task. Anim Cogn 17:701-713. https://doi.org/10.1007/s1007 1-013-0702-3

Nawroth C, Brett JM, McElligott AG (2016) Goats display audiencedependent human-directed gazing behaviour in a problemsolving task. Biol Lett 12:20160283. https://doi.org/10.1098/ rsbl.2016.0283

Passalacqua C, Marshall-Pescini S, Barnard S, Lakatos G, Valsecchi P, Prato Previde E (2011) Human-directed gazing behaviour in puppies and adult dogs, Canis lupus familiaris. Anim Behav 82:1043-1050. https://doi.org/10.1016/j.anbehav.2011.07.039

Persson ME, Roth LSV, Johnsson M, Wright D, Jensen P (2015) Human-directed social behaviour in dogs shows significant heritability. Genes Brain Behav 14:337-344. https://doi.org/10.1111/ gbb. 12194

Pfungst O (1907) Das Pferd des Herrn von Osten: der kluge Hans. Ein Beitrag zur experimentellen Tier- und Menschen-Psychologie. Barth, Johann Ambrosius, Leipzig

Proops L, Rayner J, Taylor AM, McComb K (2013) The responses of young domestic horses to human-given cues. PLoS One 8:e67000. https://doi.org/10.1371/journal.pone.0067000

Reid PJ (2009) Adapting to the human world: dogs' responsiveness to our social cues. Behav Process 80:325-333. https://doi. org/10.1016/j.beproc.2008.11.002

Riedel J, Schumann K, Kaminski J, Call J, Tomasello M (2008) The early ontogeny of human-dog communication. Anim Behav 75:1003-1014. https://doi.org/10.1016/j.anbehav.2007.08.010

Sankey C, Richard-Yris M-A, Leroy H, Henry S, Hausberger M (2010) Positive interactions lead to lasting positive memories in horses, Equus caballus. Anim Behav 79:869-875. https://doi. org/10.1016/j.anbehav.2009.12.037

Scandurra A, Prato-Previde E, Valsecchi P, Aria M, D’Aniello B (2015) Guide dogs as a model for investigating the effect of life experience and training on gazing behaviour. Anim Cogn 18:937-944. https://doi.org/10.1007/s10071-015-0864-2

Tallet C, Veissier I, Boivin X (2009) How does the method used to feed lambs modulate their affinity to their human caregiver? Appl Anim Behav Sci 119:56-65. https://doi.org/10.1016/j.appla nim.2009.03.012

Tanida H, Miura A, Tanaka T, Yoshimoto T (1995) Behavioral response to humans in individually handled weanling pigs. Appl Anim Behav Sci 42:249-259. https://doi.org/10.1016/01681591(94)00545-P 
Teglas E, Gergely A, Kupan K, Miklósi A, Topál J (2012) Dogs’ gaze following is tuned to human communicative signals. Curr Biol 22:209-212. https://doi.org/10.1016/j.cub.2011.12.018

Terlouw EMC, Porcher J (2005) Repeated handling of pigs during rearing. I. Refusal of contact by the handler and reactivity to familiar and unfamiliar humans. J Anim Sci 83:1653-1663. https://doi. org/10.2527/2005.8371653x

Udell MAR, Dorey NR, Wynne CDL (2008) Wolves outperform dogs in following human social cues. Anim Behav 76:1767-1773. https ://doi.org/10.1016/j.anbehav.2008.07.028

Udell MA, Dorey NR, Wynne CD (2010) What did domestication do to dogs? A new account of dogs' sensitivity to human actions. Biol Rev Camb Philos Soc 85:327-345. https://doi.org/10.1111/j.1469185X.2009.00104.X
Waiblinger S, Boivin X, Pedersen V, Tosi MV, Janczak AM, Visser EK, Jones RB (2006) Assessing the human-animal relationship in farmed species: a critical review. Appl Anim Behav Sci 101:185242. https://doi.org/10.1016/j.applanim.2006.02.001

Wynne CDL, Udell MAR, Lord KA (2008) Ontogeny's impacts on human-dog communication. Anim Behav 76:e1-e4. https://doi. org/10.1016/j.anbehav.2008.03.010

Zaine I, Domeniconi C, Wynne CD (2015) The ontogeny of human point following in dogs: When younger dogs outperform older. Behav Process 119:76-85. https://doi.org/10.1016/j.bepro c.2015.07.004 